\title{
Modeling Diversification and Economic Growth in the GCC Using Artificial Neural Networks
}

\author{
Mona R. El Shazly ${ }^{{ }^{*}}$ and Alice Lou ${ }^{2}$ \\ ${ }^{1}$ Division of Business, Entrepreneurship and Technology, Columbia College, Columbia, SC USA \\ ${ }^{2}$ LendingTree, Charlotte, NC USA \\ Email: ${ }^{1}$ melshazly@columbiasc.edu, ${ }^{2}$ alice.lou@lendingtree.com
}

\begin{abstract}
Despite their diversity, the Gulf Cooperation Council (GCC) states share a common threat that stems from their dependency on oil revenues. Though oil is what fueled their economic growth, its extreme price volatility proved to be a major destabilizing force to their path of sustainable and stable economic development. In response, diversification strategies to reduce their exposure were adopted by member countries with varying degrees of success. This paper analyzes the relationship between economic growth and three economic diversification indicators: export diversification index, export quality index and fiscal breakeven oil price. The model's architectural design is a hybrid system that combines artificial neural networks with genetic training. Connections between the three diversification indicators and economic growth are measured to determine the strength of their transmission pulse to each of the six GCC states and to form inferences on their impact on economic stabilization.
\end{abstract}

Keywords: economic growth, GCC diversification, oil dependency

\section{Introduction}

The Gulf Cooperation Council (GCC) was established in 1981 as an economic and political alliance of six countries: Bahrain, Kuwait, Oman, Qatar, Saudi Arabia and the United Arab Emirates. These countries share a number of common characteristics that are rooted in their Arab and Islamic culture. Even though the GCC states are diverse in size, demography, wealth and economic structure, their heavy reliance on oil, an exhaustible resource whose price is highly volatile, exacerbates their prospects for economic growth and stability.

The GCC economy has a population of approximately 50 million inhabitants, produces an aggregate GDP of about $\$ 1.6$ trillion (2013 figures), with the oil and gas sector contributing more than one half of their GDP. Saudi Arabia is the largest of the six countries, with about 29 million inhabitants accounting for over half of the region's total GDP. The other five countries are considerably smaller. The second largest is the UAE, a confederation of seven emirates: Abu Dhabi, Dubai Sharjah, Ajman, Ras El Kheimah, Umm al Qaiwain and Fujairah, with 9.3 million people producing roughly a quarter of total GCC's GDP. Key common features are a high dependency on hydrocarbons (as expressed in the share of oil and gas revenues in total fiscal and export revenues), a young and rapidly growing national labor force, and a heavy reliance on expatriate labor in the private sector [1].

These features affect the region's plans for generating sustainable economic development by presenting them with three key challenges namely: (i) an increased need for diversification away from oil and gas; (ii) privatization, liberalization and efficiency-recovering initiatives in view of the large size of the government sector; and (iii) reforms to labor market and educational systems that can generate employment opportunities for a young and rapidly growing population.

To further strengthen their ties, member states of the GCC had to undertake state and regional reforms. These reforms included the financial sector, foreign direct investments, state enterprise and privatization and the labor market [2].

Financial sector reforms were determined to be critical in promoting and supporting economic activity by extending credit, equity, and debt financing of entrepreneurial pursuits. Moreover, the financial sector aimed at regulating the securities market, revamping banking laws and ensuring compliance on money laundering. Plans to boost the private sector's participation in economic activity through the sale 
of state-owned enterprises were perceived as a panacea to the fiscal deterioration of the GCC states. Declining oil revenues coupled with spending commitments required to pacify public's angst accentuated the speed of transformation. The rhetoric behind privatization suggests that it is intended to improve enterprise performance while relieving budgetary pressures by simultaneously generating revenues and cutting expenditures.

Saudi Arabia serves as the most notable example of such efforts when in 2016 it announced that it would be planning a listing of $5 \%$ stake in the world's largest oil company Saudi Aramco with a declared valuation of $\$ 2$ trillion making it the biggest IPO on record. Other countries such as Kuwait planned to increase joint ventures between public and private sectors, allowing private share acquisition of its petroleum corporation. Similarly, Dubai and Oman announced similar privatization plans of their state owned energy companies [3].

As for the labor market reforms, GCC governments face serious employment challenges. Currently, the governments have to reconcile between the two objectives: privatization and employment. While privatization centers on operational efficiency and improved productivity, employment regulations limit the ability of their success. Pressures exerted by a growing youth population lacking in skills and education, together with labor regulation compliance requiring employers to meet quotas by hiring nationals makes the two goals incompatible.

Serving as a backdrop, the argument in support of diversification is presented in section 2 of the paper. A detailed description of three diversification indicators that are used as gauges to measure their relationship to economic growth for the six GCC states are discussed in section 3. The neural network model description is presented in section 4 with the results reported and discussed in the last section.

\section{The Case for Economic Diversification}

Extreme oil price volatility has uncovered the GCC states' vulnerabilities and exposed the symbiotic link that ties their governments to oil revenues. Though for the past twenty years efforts towards diversification have been underway, it was not until 2014 that their economic outlook was sharply altered. The deep and prolonged decline in oil prices served as a "crude awakening" [4] that forged the adoption of ambitious diversification programs that centered on the concept of "knowledge economies" that are driven by advanced research, innovation and globally competitive economic sectors [5].

Diversification strategies by member states have been adopted with ambitious targets by way of plans towards transitioning towards a diversified economy. The visions were set out as long term objectives that spanned over a ten-year period [6].

Table 1. GCC Visions

\begin{tabular}{lll}
\hline Year & Country & Vision \\
\hline 1995 & Oman & Oman 2020: Visions for Oman's Economy \\
2008 & Bahrain & Economic Vision 2030 \\
2008 & Qatar & Qatar National Vision 2030 \\
2010 & Kuwait & Kuwait Vision 2035 \\
2010 & UAE & Vision 2021 \\
2016 & Saudi Arabia & Saudi Vision 2030 \\
2017 & Kuwait & New Vision 2035 \\
\hline
\end{tabular}

The macroeconomic framework that was designed had to be delicately woven with the socio-political structure that characterizes each of the states. A more detailed framework of the key recommendations to economic diversification is presented in Appendix 1. Because of the intricate nature of the underlying relationships, the measures that were taken generated watered-down policies. Despite the planning, diversification strategies have to date yielded lackluster results.

The oil sector continues to dominate the region's economic activity and plays a significant role in determining fiscal revenues and export earnings. As such, extreme swings in oil prices directly increase fiscal budgetary exposure threatening the sustainability and momentum of economic progress. During periods of high oil prices, state budgets rise and surpluses accumulate. This encourages government 
spending to grow and finance a welfare system that is deeply entrenched in their societal structure. Likewise, when oil prices collapse, revenues shrink and reserves are depleted, as governments are unable to reduce their expenditures.

Fiscal expenditure responsiveness, however, proved to be asymmetrical to oil price changes. The reaction to declining prices on fiscal budgets is muffled compared to that of increasing prices making budgetary balances harder to maintain. Internal pressures generated by a young population whose expectations of government welfare support is perceived as being a right rather than a privilege, imposes restrictions on fiscal spending reductions when petro dollar revenues decline. This coupled with the external pressures stemming from regional unrest of neighboring "Arab Spring" countries further limit the ability of the GCC states to take on the necessary measures to balance their budgets.

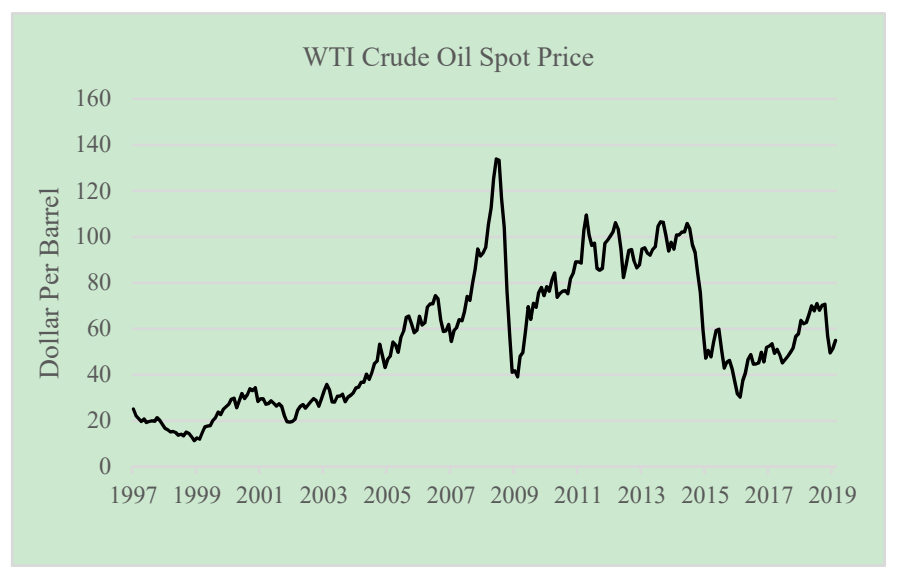

Figure 1. Crude Oil Prices 1997-2019

The premise on which economic diversification rests is that it shields oil dependent countries by reducing the impact of transmission of volatile oil prices on governmental budgets. As shown in Figure 1 crude oil prices were generally high in the early 2000s peaking at $\$ 140 /$ barrel in 2007 before spiraling down to $\$ 35 /$ per barrel in 2016 .

This paper puts to the test the case for diversification by measuring the connection strengths that links diversification indicators to economic growth. A hybrid neural network model is designed to measure the relationship between them. The section that follows describes the indicators used in the neural network model.

\section{Stylized Facts on Diversification Indicators}

Diversification has been defined as a shift in the production structure that exhibits variations that include a wider scope of products and trading partners, i.e. more extensive, as well as having better quality - intensive. As such, when exports are driven by a few sectors or a small number of trading partners, the country is considered to be less diversified. The three diversification gauges are:

1. Export Diversification Index

2. Export Quality Index

3. Fiscal Breakeven Oil Prices

\subsection{Export diversification Index}

This indicator is used to measure the horizontal dimension of export diversification by looking at export expansion across sectors. To evaluate the degree of diversification of exports, the Theil index is constructed allowing its decomposition into the extensive and intensive margins [7] [8]. The extensive Theil index is calculated for each country/year pair as:

$$
T B=\Sigma k\left(N_{k} / N\right)\left(\mu_{k} / \mu\right) \ln \left(\mu_{k} / \mu\right)
$$


where $k$ represents each group (traditional, new, and non-traded), $N_{k}$ is the total number of products exported in each group, and $\mu_{k} / \mu$ is the relative mean of exports in each group.

The intensive Theil index for each country/year pair is:

$$
T W=\Sigma k\left(N_{k} / N\right)\left(\mu_{k} / \mu\right)\left\{\left(1 / N_{k}\right) \Sigma i \in I_{k}\left(x_{i} / \mu_{k}\right) \ln \left(x_{i} / \mu_{k}\right)\right\}
$$

where $x$ represents export value.

\subsection{Export Quality Index}

Focus of this index is on the vertical dimension of production and exports by measuring quality upgrades. Because quality upgrades cannot be directly observed, average export prices are used as a proxy for it. A number of methodologies have been used to estimate export quality, in this paper however, we use the database provided by the IMF that relies on the approach developed by Henn, Papageorgiou and Spatafora [9].

\subsection{Fiscal Breakeven Oil Prices}

As an indicator, the fiscal breakeven oil price estimates the minimum oil price required to match the government's need to meet its spending commitments while balancing the budget. Fiscal breakeven prices have recently gained popularity amongst analysts and decision makers alike who use it to extrapolate information related to market dynamics and geopolitical inferences. Though its valuation provides important insights, it must be used and interpreted with extreme caution as inferences made by it are often used as a basis for policy advice and recommendations that have serious ramifications.

A detailed discussion of the uses and abuses of fiscal breakeven oil prices is presented by Clayton and Levi [10]. As any indicator, the information extrapolated from it should be aligned with what it actually measures avoiding pitfalls that can result from misinterpretation.

Breakeven oil prices could be used as a predictor of oil production and future global oil supplies and prices for countries that aim to balance their budgets. If oil prices fall below the breakeven, fiscal budgets will be adversely affected prompting governments to revise their production policy so as to offset the revenue losses attributed to the lower than budgeted price. This would especially be true if these governments believed that their action would not affect world prices.

Another use of breakeven prices is implementing it as a tool to promote fiscal reforms. Policymakers can use it as a proxy for their economic resilience. By highlighting the link between global oil prices and sustainable spending habits, governments are enabled to convey to their citizens the need for diversification urgency of implementing subsidy reforms.

The pitfalls to avoid in using breakeven oil prices are related to extending the limits of their application by drawing conclusions related to geopolitics and on stability assessment. Another danger is using the estimate as a predictor of future oil prices. This is especially true because of the way this estimate is measured is not consistent and wide variations are reported depending on the methodology applied.

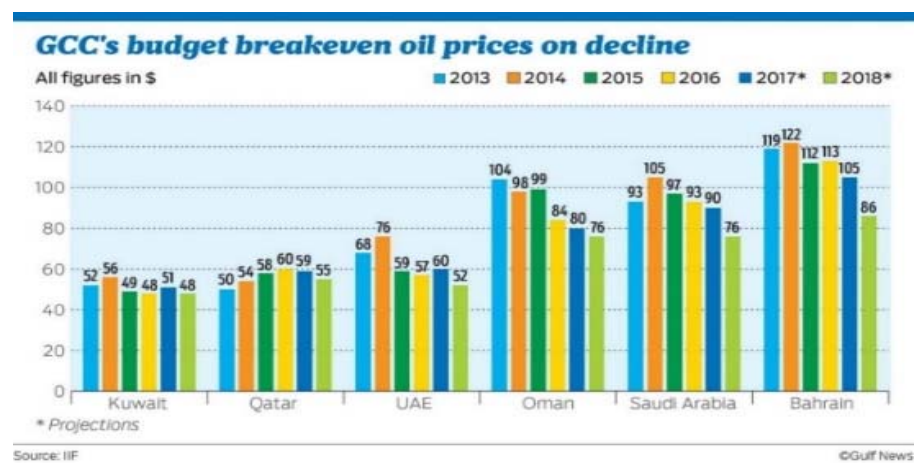

Figure 2. GCC's Budget Breakeven Oil Prices 
As shown in Figures 2 and 3 the breakeven price of oil for the GCC states has been declining since 2014 for all of the six GCC states. Fiscal breakeven price of oil would drop if from the revenue side the value of hydrocarbon and non- hydrocarbon exports generated by the government increases and or fiscal expenditure declines. It is worth noting as reported in Table 2 that while in 2017 the lower breakeven price is attributed to a reduction in government spending, in 2018 non-oil revenues have been identified as being the primary reason for that decline [11] [12].

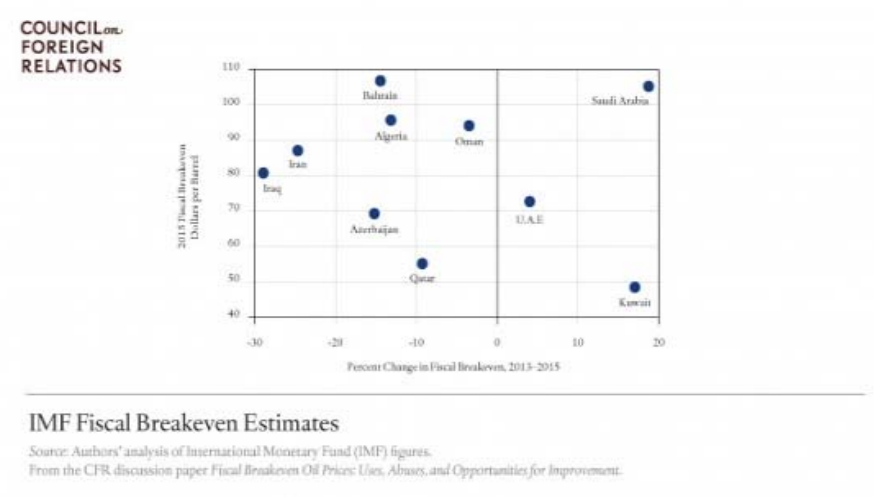

Figure 3. IMF Fiscal Breakeven Estimates

Table 2. GCC Total Expenditure (USD Billion)

\begin{tabular}{llllll}
\hline & $\mathbf{2 0 1 6}$ & $\mathbf{2 0 1 7 E}$ & $\mathbf{2 0 1 8 F}$ & Change 2017 & Change 2018 \\
\hline Bahrain & 11.3 & 11.8 & 11.9 & $4.5 \%$ & $0.6 \%$ \\
Oman & 34.1 & 33.1 & 34.1 & $-3.1 \%$ & $3.0 \%$ \\
Qatar & 58.0 & 55.8 & 56.8 & $-3.8 \%$ & $1.8 \%$ \\
Kuwait & 58.7 & 60.6 & 63.4 & $3.4 \%$ & $4.6 \%$ \\
UAE & 113.6 & 115.2 & 118.3 & $1.4 \%$ & $2.7 \%$ \\
Saudi Arabia & 249.5 & 228.2 & 247.8 & $-8.5 \%$ & $8.6 \%$ \\
\hline
\end{tabular}

\section{Model Architectural Design}

The model was designed, trained and tested using the Brainmaker software that was developed by California Scientific. Raw annual data covering the period 1982-2016 was fed in the network for each of the six states of the GCC. The basic ANN model was combined with a genetic optimizer GTO to form the hybrid network so as to enhance the models' performance. The export diversification and quality database were compiled by the IMF. The Export Diversification Database has three main indicators: the Export Diversification Index, the Extensive Margin, and the Intensive Margin. Higher values for the all three indices indicate lower diversification. The Export Quality Database contains export quality measures across different aggregation levels of export products. Higher values for the quality indices indicate higher quality levels [7]. Fiscal oil breakeven price is defined as the price that is required to generate a balanced government budget [10].

The model's architecture design is that of a multi-layer perceptron. The network undergoes a process of supervised training until a desired pre-specified level of accuracy is achieved. During training, weights are assigned randomly between nodes. Guesses are generated and compared with actual values and an error term is calculated. The error is then backpropagated and weights are adjusted accordingly. Model testing is conducted once training is complete and networks are rated based on their performance [13].

Selected networks are then subject to a Genetic Training Optimizer (GTO) to further enhance their performance. GTO is a technique that is based on the concept of biological improvement. Genetic algorithms are a class of probabilistic research techniques based on biological evolution. Their search is based on computationally simulated version of "survival of the fittest". In search for the optimal solution, the algorithm mimics the process of natural selection by testing the fitness of the individuals 
(networks) to determine if they will be allowed to reproduce. The genes of the "good" or "fit" network are mutated to create another "parent" network. The two networks are then crossed over to create to create a new "child" network. If the child network outperforms one or both parents, it is saved and used for reproducing even better generations of future networks [14].

The process of genetic evolution is initiated by randomly selecting a population and evaluating each of its members. Three operators are then applied to all candid solutions: reproduction, crossover and mutation evolution. Reproduction allows relatively fit networks to survive and procreate. The process is asexual with the hopes that it could improve on the fitness levels. Crossover represents a way of moving through the space of possible solutions based on information gained from existing solutions. As an operator, crossover is described in terms of exploitation of information in good individuals, and is similar to "artificial mating" and requires taking neurons from each parent to produce the child network. Mutation is the random adjustment of the individual's genetic structure. As an operator, mutation is described as the exploration of the search space, it requires one parent, and is conducted by a random modification of the neuron weights [14].

The data set is divided into two sets; one is for training, utilizing $80 \%$ of the facts, while the remaining $20 \%$ are reserved for testing. Training consists of running patterns through the network forward then propagating the errors backwards, and updating the weights accordingly. Once networks are identified as being "good" they are saved and subject to genetic training further

Unlike traditional techniques, GAs seek to identify optimal solutions by searching entire populations of candid solutions in parallel. The advantage to this approach is that it is more likely to estimate the true global optimum, and much less likely to be stuck at a local optimum. Another appealing feature of GAs is that their performance is largely unaffected by initial conditions. Furthermore, they are capable of finding relationships between inputs and outputs even when patterns are ill defined.

\section{$5 \quad$ Empirical Results}

Each of the six network models: Bahrain, Kuwait, Oman, Qatar, Saudi Arabia and the United Arab Emirates were run separately and their results are reported in Appendix 2. The network parameters are given in the first row of the connection weights for the GTO optimizer with the numbers $3 \quad 1 \quad 3 \quad 101$. The first number, three, is for the number of nodes in the input layer, which in the model represents the diversification indicators. The number that follows is one, for threshold function. The second number three, specifies the number of layers in the ANN model (input, hidden and output). The hidden layer that connects the input with the output layer has ten nodes. The last number one represents the number of nodes in the output layer, which for our model is GDP.

The weight matrix reported in Appendix 2 reflects the impact each input has on the overall solution based on the knowledge gained by the system. During both training and testing, the tolerance level was set at 0.10 . The transfer function used between layers is the sigmoid transfer function that works well with backpropagation. The network's performance is evaluated by how well the output matches the pattern. The values reported in Table 3 have a range of $0.83-0.98$ indicating that the model has a good fit based on the $\mathbf{R}^{2}$.

Table 3. Goodness of Model's fit $\mathrm{R}^{2}$

\begin{tabular}{ll}
\hline Country & $\mathbf{R}^{2}$ \\
\hline Bahrain & 0.9659 \\
Kuwait & 0.9727 \\
Oman & 0.9632 \\
Qatar & 0.9735 \\
Saudi Arabia & 0.9832 \\
UAE & 0.8304 \\
\hline
\end{tabular}

In Table 4 the relationships the three inputs: Oil Breakeven Price, Export Quality and Export Diversification have on each country's GDP are reported. The absolute mean coefficient measures the effect the input has over all the facts, or its overall effect. While export diversification is the most 
significant indicator of diversification for Bahrain and Kuwait, oil breakeven prices is for Oman, Qatar, Saudi Arabia and the United Arab Emirates. Of the three indicators, export quality for all six states has the lowest mean effect on GDP, which may be explained by the qualitative nature of the indicator and inaccuracy in measurement.

Connection strengths for export diversification are highest for Kuwait and Bahrain. While Kuwait for the period understudy has been able to manage its fiscal balances with the lowest breakeven oil price \$48, Bahrain on the other hand has had the highest built in breakeven oil prices of $\$ 122$ in 2014 . Following the price collapse of 2014, Bahrain was able to reduce its breakeven oil price by more than $30 \%$ by adopting strict export diversification initiatives that support the results of our study.

Table 4. Absolute Mean Effect of Diversification Indicators on GDP

\begin{tabular}{llll}
\hline & Oil Breakeven Price & Export Quality & Export Diversification \\
\hline Bahrain & 0.0974 & 0.0581 & $\mathbf{0 . 1 4 4 0}$ \\
Kuwait & 0.1162 & 0.0875 & $\mathbf{0 . 1 1 9}$ \\
Oman & $\mathbf{0 . 1 2 3 1}$ & 0.0110 & 0.0320 \\
Qatar & $\mathbf{0 . 1 4 2 2}$ & 0.0187 & 0.0580 \\
Saudi Arabia & $\mathbf{0 . 1 4 0 4}$ & 0.0757 & 0.0805 \\
UAE & $\mathbf{0 . 1 3 0 1}$ & 0.0288 & 0.0481 \\
\hline
\end{tabular}

There are two long- standing and seemingly opposing views on international trade and economic growth and development. The first can be traced to the Classical view of trade which advocates specialization and trade based on an advantage a country possess (absolute, comparative or factor endowment) emphasizing the welfare gains to the country and the world resulting from specialization. The second viewpoint heralds the merits of diversification by sounding off the risks from concentration through specialization. The premise in support of diversification rests on risk reduction stemming from volatility paving the path to macroeconomic stability. As such, diversification is promoted and is associated with higher output, income and employment.

In an effort to reconcile the two views, we need to carefully consider the following:

- The stage of the country's development

- Which aspects of diversification are important

- What are the underlying country specific conditions: social, political, cultural

- Moreover, in today's global world where markets are interdependent and integrated, can diversification reduce risk? How much insulation does diversification provide? Those are some of the questions that must be answered before evaluating performance and policy effectiveness.

Though the results of this research lack firm conclusion on the relationship between diversification and economic growth, there is widespread consensus amongst researchers and practitioners alike that holds that oil prices are converging to a lower long-term trend. As such, the GCC states need to reconsider their growth model and their underlying social contracts. To achieve this transformation, a carefully balanced approach that factors both internal and external pressures must be designed and managed. Employment pressures and increased popular demands for political change to allow governance that is more democratic have to be interwoven in the transformation matrix.

Unlike the populous oil Arab countries that have experienced the "oil curse", the GCC states have been able to avoid many of the problems because of their deep fiscal pockets. Massive funds poured towards financing infrastructural developments, support of social programs, and provision of public sector work for nationals, shielded governments from peoples' angst generated from adverse oil price shocks. So much so that through their generous spending, they were even able to defy the basic tenant that holds that non-democratic governments adversely affects economic growth and stability [19].

Looking forward, questions surrounding economic and political sustainability of the status quo starkly stand out. Will the GCC be able to initiate and implement the needed changes that would insulate them from the pressures they face enabling them to fully integrate into the global framework? 


\section{Appendix 1. Key Recommendations to Economic Diversification IMF 2016, Economic Diversification in Oil -Exporting Arab Countries}

\subsection{Macroeconomic Pre-Conditions to Economic Diversification}

- Develop a robust fiscal framework based on a fiscal rule, to help achieve short and long-term objectives.

- Ensure that the use of oil funds is governed by clear and transparent rules.

- Improve liquidity management, including liquidity forecasting and the interbank market operations.

- Develop strong regulatory, supervisory and macro-prudential frameworks to enhance resilience of the financial sector to the volatility of oil prices.

- Promote a fairly valued real effective exchange rate.

\subsection{Regulatory and Institutional Framework Conductive to Private Sector Growth}

- Streamline government bureaucracy.

- Reduce regulatory barriers to competition, including reviewing competition policy laws and their implementation.

- Promote greater trade integration

- Review labor regulations to enhance labor market flexibility where needed (e.g., streamline regulations, facilitate labor dispute resolution, and set incentives for higher women participation in the labor force) while fostering better working conditions.

- Reduce directed lending and develop domestic securities markets to increase access to finance. Improve creditor assessment tools and infrastructure and creditor rights to enhance access to credit, especially for small and medium enterprises (SMEs).

\subsection{A Public Sector that Enables Private Sector Growth}

- Reduce the size of the public work force and the premium of public over private sector wages for comparably qualified employees. Implement civil service review.

- Increase public spending on education if it is low.

- Enhance the quality of education, including orienting education and vocational training towards skills needed by the private sector.

- Introduce/improve unemployment insurance schemes to ensure the unemployed receive minimum income but have proper incentives to look for work.

- Invest in infrastructure while increase the efficiency of public investment.

- Enhancing bidding procurement processes.

\subsection{The Road to a More Diverse Economy}

- Improve the climate for FDI, including in non-oil industry, by lowering entry requirements, creating investment promotion intermediaries and streamlining tax structures.

- Promote deeper integration in global value chains by enhancing efficiency in production, bolstering managerial quality, improving technological capacity and ensuring wage competitiveness.

- Support horizontal diversification by enhancing allocation of government oil revenues in a manner that reduces production costs in new sectors and raises their efficiency while encouraging entry of new investors.

- Enhance vertical diversification in existing sectors by focusing on moving into higher value-added products in the mineral and chemical industries.

- Enhance labor market competitiveness through greater focus on wage growth in line with productivity. 


\section{Appendix 2. Connection Weights}

Bahrain

\begin{tabular}{|l|l|l|l|l|l|}
\hline weights & 3 & 1 & 3 & 10 & 1 \\
\hline
\end{tabular}

\begin{tabular}{|l|l|l|l|}
\hline 4.6362 & 7.8160 & 2.9824 & 1.8306 \\
\hline-1.3400 & 1.3376 & -7.9546 & 4.9756 \\
\hline-7.5242 & 4.1406 & 7.2622 & 2.2804 \\
\hline 5.9556 & 2.4340 & -6.4452 & 1.1064 \\
\hline-6.5610 & -4.7150 & -1.7952 & -5.0114 \\
\hline-4.0350 & -3.2782 & -3.5124 & 6.3926 \\
\hline-0.4562 & 1.4116 & -7.2424 & 3.9122 \\
\hline-7.1020 & 1.8264 & -1.9104 & 5.7424 \\
\hline 3.6826 & -4.2154 & -5.1346 & 4.1266 \\
\hline-6.0952 & 3.2806 & -2.9220 & -3.0450 \\
\hline
\end{tabular}

$1.8912-1.0986-3.24204 .15703 .34003 .6356-5.5046-4.5414-6.0950-0.85244 .2122$

\section{Kuwait}

\begin{tabular}{|l|l|l|l|l|l|}
\hline weights & 3 & 1 & 3 & 10 & 1 \\
\hline
\end{tabular}

\begin{tabular}{|l|l|l|l|}
\hline 1.6350 & -0.3602 & -1.0314 & -1.2152 \\
\hline-0.8046 & 0.3506 & -5.3896 & 5.0872 \\
\hline 0.4146 & 1.4216 & 5.2362 & -7.1252 \\
\hline-6.1494 & -5.3316 & 7.8954 & 3.2250 \\
\hline 6.8460 & -6.5574 & -6.4786 & -4.8266 \\
\hline 6.3452 & 3.5686 & 7.2904 & -6.6236 \\
\hline-0.1146 & 0.2466 & -3.1146 & 4.4414 \\
\hline 2.3000 & 3.3732 & 7.1566 & -7.8464 \\
\hline-3.4554 & -4.2220 & -4.3474 & -0.7574 \\
\hline-6.9656 & 4.2470 & 1.7010 & 3.4922 \\
\hline
\end{tabular}

$1.8286-4.51406 .5866-5.8300-5.50427 .0984-5.3964-1.9150-3.12644 .82160 .0596$

\section{Oman}

\begin{tabular}{|l|l|l|l|l|l|}
\hline weights & 3 & 1 & 3 & 10 & 1 \\
\hline
\end{tabular}

\begin{tabular}{|l|l|l|l|}
\hline-3.3242 & -4.4746 & 0.7774 & 0.8594 \\
\hline-4.4290 & 0.1670 & -2.2376 & 2.3246 \\
\hline 0.0208 & 0.4832 & 4.8770 & -4.7600 \\
\hline-1.0386 & -0.7454 & -0.0222 & 2.7812 \\
\hline 5.2676 & 1.3212 & -1.0924 & 0.6646 \\
\hline-1.1560 & -5.3410 & 1.6974 & -3.5226 \\
\hline 2.8990 & -0.8914 & -0.0754 & -1.6344 \\
\hline-2.0530 & -0.9102 & -4.2680 & 4.9566 \\
\hline-4.0760 & 0.4008 & -1.1894 & 1.2744 \\
\hline-7.1000 & 3.0130 & -2.0292 & 2.1836 \\
\hline
\end{tabular}

$-1.0960-2.8422-2.2624-1.66840 .8060-3.59102 .96962 .6846-2.7222 \quad 1.6622-0.8100$ 
Qatar

\begin{tabular}{|l|l|l|l|l|l|}
\hline weights & 3 & 1 & 3 & 10 & 1 \\
\hline
\end{tabular}

\begin{tabular}{|l|l|l|l|}
\hline-3.3474 & -0.9480 & 1.8908 & 2.0826 \\
\hline-3.8984 & 0.6604 & -0.2100 & 3.7584 \\
\hline-3.7674 & -0.2292 & 4.3882 & -5.7604 \\
\hline-3.2072 & -1.5142 & 2.2444 & 3.7946 \\
\hline 1.4124 & 3.3308 & 0.1394 & 5.0902 \\
\hline 0.0614 & -1.4052 & 0.4008 & 2.9556 \\
\hline 4.8534 & -2.3710 & -1.3132 & -3.2306 \\
\hline 0.0882 & 0.5892 & -2.5626 & -2.7650 \\
\hline-1.9534 & -0.4566 & 1.0990 & 0.8664 \\
\hline 2.5400 & 0.9300 & -4.9186 & 0.3214 \\
\hline
\end{tabular}

$-0.7014-3.6350-5.0474-2.65821 .14921 .16546 .00602 .5696-3.88221 .7624-0.0144$

Saudi Arabia

\begin{tabular}{|l|l|l|l|l|l|}
\hline weights & 3 & 1 & 3 & 10 & 1 \\
\hline
\end{tabular}

\begin{tabular}{|l|l|l|l|}
\hline 7.1474 & 0.7506 & -3.1560 & 4.0894 \\
\hline-6.0010 & -4.3392 & 0.5304 & -2.2432 \\
\hline 3.9384 & 4.2120 & -5.5280 & 6.7506 \\
\hline 6.8294 & -5.3242 & 2.7000 & -3.3724 \\
\hline 4.3462 & -3.4450 & -7.1174 & 4.3696 \\
\hline 2.3064 & 0.1516 & 0.9662 & 3.6994 \\
\hline 7.5026 & -0.3790 & -1.0364 & 7.4384 \\
\hline 5.9866 & 7.2032 & -7.9072 & -2.9090 \\
\hline-0.8140 & -2.2974 & 5.8872 & 3.6880 \\
\hline-6.3224 & -1.9280 & -1.6850 & 4.5004 \\
\hline
\end{tabular}

$4.1190-0.3512-2.44347 .0930-2.5390-3.4926-4.14765 .7064-2.97523 .96364 .5060$

United Arab Emirates

\begin{tabular}{|l|l|l|l|l|l|}
\hline weights & 3 & 1 & 3 & 10 & 1 \\
\hline
\end{tabular}

\begin{tabular}{|l|l|l|l|}
\hline 3.2750 & -4.2260 & 4.3386 & -6.1808 \\
\hline-3.3342 & 3.1522 & -1.6956 & 5.4426 \\
\hline-1.2484 & -0.3062 & 2.9676 & 3.2102 \\
\hline-5.4790 & -0.2612 & -6.3854 & -3.7008 \\
\hline-0.5034 & 0.9412 & 2.4104 & 2.8472 \\
\hline 7.9236 & 0.2332 & -2.9196 & -2.5742 \\
\hline 2.5984 & -0.5036 & -6.3534 & -5.1536 \\
\hline 6.5246 & 7.6690 & -5.8422 & 2.7114 \\
\hline 7.5534 & 5.1590 & -3.8270 & 1.8924 \\
\hline 6.7754 & 1.2800 & -3.4726 & -3.9046 \\
\hline
\end{tabular}

$-0.38643 .26501 .02564 .81062 .82947 .1652-4.3402-3.1892-3.0704-2.3314-3.7660$ 


\section{References}

1. "DataBank: World Development Indicators," The World Bank, [Online]. Available: https://databank.worldbank. org/data/reports.aspx?source=2\&series=NY.GDP.MKTP.CD. [Accessed 193 2019].

2. U. Fasano and Z. Iqbal, "GCC Countries: From Oil Dependence to Diversification," International Monetary Fund, 2003.

3. A. Diwakar, "The Region: Privatization as Reform: The Solution for GCC Economies?," 2110 2017. [Online]. Available: https://theregion.org/article/11821-privatization-as-reform-the-solution-for-gcc-economies. [Accessed $1632019]$.

4. M. El Shazly, "Saudi Arabia's Crude Awakening," Journal of Advances in Economics and Finance, pp. 105-119, November 2018.

5. K. C. Ulrichsen, "Economic Diversification in Gulf Cooperation Council (GCC) States," in Center of Energy Studies, Rice University, June 2017.

6. M. Hvidt, "Economic Diversification in GCC Countries: Past Record and Future Trends," London School of Economics and Political Science, London, UK, 2013.

7. "IMF Data: Export Diversification and Quality," IMF, [Online]. Available: http://data.imf.org/?sk=A093DF7DE0B8-4913-80E0-A07CF90B44DB. [Accessed 153 2019].

8. IMF, The Diversification Toolkit: Export Diversification and Quality Databases, IMF, 2017.

9. C. Henn, C. Papageorgiou and N. Spatafora, "Export Quality in Developing Countries," IMF Working Paper, vol. May, no. 13/108, 2013.

10. M. A. Levi and B. Clayton, "Fiscal Breakeven Oil Prices: Uses, Abuses, and Opportunities for Improvement," Council on Foreign Relations, 3011 2015. [Online]. Available: https://www.cfr.org/report/fiscal-breakeven-oilprices. [Accessed 203 2019].

11. Marmore: MENA Intelligence, "Why are the breakeven oil prices coming down for GCC countries?," 1112018. [Online]. Available: https://www.e-marmore.com/Blog/Economy/January-2018/Why-are-the-breakeven-oilprices-coming-down-for-G.

12. M. R. Raghu, "The National: How GCC states' break-even oil prices stack up," 248 2015. [Online]. Available: https://www.thenational.ae/business/how-gcc-states-break-even-oil-prices-stack-up-1.19805. [Accessed 24 2019].

13. M. R. El Shazly and H. E. El Shazly, "Forecasting Currency Prices using a Genetically Evolved Neural Network Architecture," International Review of Financial Analysis, vol. 8, no. 1, pp. 67-82, 1999.

14. J. Kingdon, Intelligent Systems and Financial Forecasting, London, UK: Springler-Verlag Publishers, 1997.

15. P. Calice, N. Mohamed and R. Behrndt, "Improving the Quality of Financial Intermediation in the Gulf Cooperation Council (GCC) Countries," GCC Enegagement Note No. 2, June 2015.

16. IMF, "Economic Diversification in Oil-Exporting Arab Countries," in Annual Meeting of Arab Ministers of Finance, Manama, Bahrain, 2016.

17. "Short-Term Energy Outlook Data Browser," U.S. Energy Information Administration EIA, [Online]. Available: https://www.eia.gov/outlooks/steo/data/browser/\#/?v=8\&f=M\&s=\&start=199701\&end=202012\&id=\&mapty pe=0\&ctype=linechart\&linechart=WTIPUUS. [Accessed 163 2019].

18. B. W. Setser and C. Frank, "Interactive: Oil Exporters' External Breakeven Prices. Council on Foreign Relations," Council on Foreign Relations, 117 2017. [Online]. Available: https://www.cfr.org/report/ interactive-oil-exporters-external-breakeven-prices. [Accessed 183 2019].

19. El Badawi, I and H. Selim, eds. Understanding and Avoiding the Oil Curse in Resource rich Arab Economies", Cambridge University Press, 2016 